\title{
Severe hyperemesis gravidarum affects offspring metabolism in childhood
}

\author{
Ahila Ayyavoo ${ }^{1,2^{*}}$, Paul L Hofman ${ }^{1,2}$, José GB Derraik', Sarah Mathai ${ }^{1}$, Peter Stone ${ }^{3}$, Frank Bloomfield ${ }^{1,2}$, \\ Wayne S Cutfield ${ }^{1,2}$ \\ From 7th APPES Biennial Scientific Meeting \\ Nusa Dua, Bali. 14-17 November 2012
}

Hyperemesis gravidarum leads to alterations in maternal (and possibly fetal) nutrition throughout pregnancy, but there are no data on the long-term metabolic health outcomes in the offspring. We hypothesized that hyperemesis gravidarum could lead to fetal nutritional compromise or physiological stress, which may programme later metabolism and body composition.

Two groups of healthy pre-pubertal children born at term, aged 4-11 years were studied: offspring of mothers who suffered hyperemesis gravidarum (HG group; $n=36$ ) and controls $(\mathrm{n}=54)$. Recruited HG children were born to mothers admitted to hospital with metabolic disturbance during pregnancy. Following an overnight fast, a frequently sampled intravenous glucose tolerance test modified by insulin was performed, and insulin sensitivity was measured using Bergman's minimal model. Other assessments included fasting lipid and hormonal profiles, as well as body composition using whole-body dual-energy $\mathrm{x}$-ray absorptiometry. Data were analysed separately using linear mixed models, controlling for appropriate confounders. Data are expressed as mean \pm SEM.

Children born to mothers with severe HG had reduced $S_{I}\left(10.4 \pm 0.6\right.$ vs $13.4 \pm 0.9 \times 10^{-4} \mathrm{~min}^{-1} \cdot(\mathrm{mU} / \mathrm{L})$; $\mathrm{p}=0.016)$, increased fasting insulin $(6.5 \pm 0.6$ vs $4.9 \pm$ $0.3 \mathrm{mIU} / \mathrm{L} ; \mathrm{p}=0.023)$, reduced IGFBP1 $(13.0 \pm 1.3 \mathrm{vs}$ $18.0 \pm 1.6 \mathrm{ng} / \mathrm{ml} ; \mathrm{p}=0.029)$ and IGFBP3 $(3017 \pm 106 \mathrm{vs}$ $3497 \pm 102 \mathrm{ng} / \mathrm{ml} ; \mathrm{p}=0.008)$ in comparison to controls. Baseline cortisol was higher in HG children $(251 \pm 13$ vs $218 \pm 11 \mathrm{nmol} / \mathrm{l} ; \mathrm{p}=0.007)$. DEXA-derived body composition was similar in HG and control groups.

Children born to mothers who experienced severe hyperemesis gravidarum were less insulin sensitive and had elevated baseline cortisol compared to controls. We

'Liggins Institute, University of Auckland, Auckland, New Zealand Full list of author information is available at the end of the article postulate that severe hyperemesis gravidarum reduces insulin sensitivity in the offspring due to fetal programming of the fetal hypothalamic-pituitary-adrenal (HPA) axis. Long-term follow up of these offspring is essential to determine later risk of metabolic disease.

\section{Authors' details}

'Liggins Institute, University of Auckland, Auckland, New Zealand. 'National Research Centre for Growth and Development, University of Auckland, Auckland, New Zealand. ${ }^{3}$ Department of Obstetrics and Gynaecology, Faculty of Medical and Health Sciences, University of Auckland, Auckland, New Zealand.

Published: 3 October 2013

doi:10.1186/1687-9856-2013-S1-051

Cite this article as: Ayyavoo et al:: Severe hyperemesis gravidarum affects offspring metabolism in childhood. International Journal of Pediatric Endocrinology 2013 2013(Suppl 1):O51.

Submit your next manuscript to BioMed Central and take full advantage of:

- Convenient online submission

- Thorough peer review

- No space constraints or color figure charges

- Immediate publication on acceptance

- Inclusion in PubMed, CAS, Scopus and Google Scholar

- Research which is freely available for redistribution

\section{Biomed Central}

